\title{
Frequency Control of Microgrid with Renewable Generation using PID Controller based Krill Herd
}

\author{
M. Regad', M. Helaimi' ${ }^{1}$, R. Taleb', Ahmed M.Othman'², Hossam A. Gabbar ${ }^{3}$ \\ ${ }^{1}$ Laboratoire Génie Electrique et Energies Renouvelables (LGEER),Electrical Engineering Department, Hassiba \\ Benbouali University, Chlef, Algeria \\ ${ }^{2}$ Electrical Power and Machine Department, Faculty of Engineering, Zagazig University, Egypt \\ ${ }^{3}$ Faculty of Energy Systems and Nuclear Science, University of Ontario Institute of Technology (UOIT), 2000 Simcoe St. \\ N., Oshawa ON L1H 7K4 ON, Canada
}

\begin{tabular}{l} 
Article Info \\
Article history: \\
Received May 1, 2019 \\
Revised Feb 26, 2020 \\
Accepted Mar 6, 2020 \\
\hline Keyword: \\
Microgrid, renewable generation \\
frequency control, optimization \\
PID controller, Genetic algorithm, \\
particle Swarm Optimization, Krill \\
Herd Algorithm, Energy Storage \\
System.
\end{tabular}

\begin{abstract}
The main of this paper is to provide optimal control of a state microgrid system. The proposed configuration composes of renewable generation systems such as solar photovoltaic systems and wind turbine generator with a Diesel Engine Generator and Fuel-Cell. An Aqua electrolyzer and other energy storage systems such as battery and flywheel are also used in the proposed microgrid. A standard PID (Proportional Integral Derivative) controller scheme is introduced whose its parameters are determined using different optimizations algorithm such as Algorithm Genetic, Particle Swarm Optimization, and Krill Herd algorithm for minimizing frequency and power deviations, in order to enhance the operation of this system. The PID controller gains are optimized by resolving an objective function. The simulation results are shown, and given that the Krill Herd algorithm improves the performance of the system in comparison with GA and PSO based on PID. The efficiency of the system is improved.
\end{abstract}

Copyright () 2019 Institute of Advanced Engineering and Science. All rights reserved.

\section{Corresponding Author:}

Regad Mohamed

Electrical Engineering Department, Hassiba Benbouali University, Chlef, Algeria

Laboratoire Génie Electrique et Energies Renouvelables (LGEER)

Email: m.regad@univ-chlef.dz

\section{INTRODUCTION}

Nowadays, the energy demand increases, coupled to the growth of consumption the rising of the greenhouse effect, has moved the world to the integration of Renewable energy technologies such as solar and wind system with other conventional energy sources [1]. The penetration of the RESs has been increased and had many advantages for the electrification of rural zones.

The big challenge in the hybrid energy system is the frequency and power controls, which have taken great importance in the microgrid operation and control in order to improve the sufficiency, reliability, and quality of power [2]. To obtain a system totally autonomous a stand-alone hybrid energy sources with storage energy systems are proposed.

Both component hybrid system and strategy control are usually used to regulate the frequency and power deviation in a linear model of Microgrid. Using renewable generation sources in a hybrid system to produce electricity has been accepted as the most economical and environment-friendly method. The hybrid power system requires more adequate control design to ensure its ability to reduce the imbalance between generated powers and demand [3-4]. The produced powers from the renewable sources are stochastic, intermittent and based on the climate conditions which might cause the unbalance between the power demand and the total power. On the other hand, using storage devices like the battery and flywheel is an 
efficient tool for improving the performance and stability of the MG systems and demining the unbalance of powers. This method can also enhance the power quality and mitigate the fluctuations of Microgrid frequency. That is making the storage devices one of the most important components of the microgrid. Flywheel Energy Storage device is useful in many industrial system due to its power density and efficiency to store and release power while short periods.

The proposed stand-alone hybrid power system consists of solar photovoltaic (PV), wind turbine generator (WTG), Fuel-Cell (FC), Diesel Engine Generator (DEG), Aqua Electrolyzer (AE) Battery Energy Storage System and Flywheel Energy Storage System as reported in [5]. The existence of the storage devices such as BESS and FESS is vital in the MG for storage the excessive power from renewable sources, if there is still surplus power; it is absorbed by the aqua electrolyzer for generating hydrogen which is stored in the hydrogen tank for it to be used by Fuel Cells as fuel. When the generated power from these renewable sources increases over the load power, the surplus is stored by energy Storage System and later discharged to load when it is required. Wind, solar, fuel cells, and diesel generator systems are the most distributed generation resources that are used in the Microgrid system. The FC and DEG are used as second-generation sources with energy storage systems like the Battery and the Flywheel to compensate for the slower response of DEG and FC. Many research towards designing a control strategy for hybrid energy system control using the standard PID controller as in [6-7] where the genetic algorithm optimizes the PI/PID controller in the hybrid energy system is discussed and robust $\mathrm{H} \infty$ controller for hybrid energy system is reported in [3]. Some works about the control design of the microgrid energy system have been accomplished like in [8-14]. Fractional Order PID controller, Fractional Order Fuzzy Controller, and Fuzzy PID controller are used for frequency control in hybrid energy systems like in [15-17] respectively.

In order to show and enhance the performances the PID controller which is not be employed in the same proposed microgrid configuration and due to the complexity of the control schemes used in the literature, this paper contributes to apply the classical PID controller based optimization techniques because of its simplicity, ease of implementation and low simulation time tuning. The present paper investigates an optimal controller in order to eliminate the power and frequency fluctuations in the proposed system configuration, which will mitigate power unbalance between the power generation and the load power. Also, it addresses the design of PID controller whose gains being optimized by three different optimization algorithms. These metaheuristics optimization methods have been largely applied to solving many complex problems. They are considered to be more effective techniques that have been applied in different kinds of structural engineering issues where conventional iterative methods fail or perform poorly.

Any PID controller gains need to be optimized in order to regulate the microgrid frequency and power deviations. It was decided to use meta-heuristic algorithms to find several possible parameter settings of the PID controller. The results are compared. There are various optimization techniques for tuning the PID controller parameters among which the Genetic Algorithm, the Particle Swarm optimization algorithm, and Krill Herd are proposed. Basics of GA, PSO, and KH are illustrated in literature as in [18-20]. GA is slower to find the optimal performances against the system uncertainties. PSO has been considered to be robust to solve continuous and non-linear optimization problems. In the literature; there is not enough study about the use of Krill Herd in the field of the hybrid energy system which leads to applying this technique to improve the system performance. In this paper, the comparative performance between these three optimization techniques has been reported through optimizing PID controller parameters in order to show the advantage of the proposed methods.

The rest of this paper is classified as follows: In Section 2, the model of proposed system and the modeling of its different components are described. In Section 3, the PID controller shame and objective function are explained. Section 4 shows the different optimization methods used in this paper. The simulation results and analysis are summarized in Section 5. Also in section 5, the potential impacts of energy storage systems on power balancing and frequency stabilization of the proposed hybrid energy system are addressed. Finally, our work was finished with a conclusion presented in section 6.

\section{HYBRID POWER SYSTEM}

The proposed configuration of the hybrid energy system with energy storage is shown in Figure 1. The renewable energy sources have intermittent nature which causes disturbances in Microgrid and affects its stability. Solar power has stochastic nature and depends on the environmental conditions over time instant. For this, a control strategy is necessary to eliminate the fluctuations in power deviation. To make the system stable some reliable sources are added, generally, a diesel generator and fuel cell are used. Some storage system is employed. The hybrid energy system composes of different DERs, i.e., PV panel, wind turbines (WT), FC, AE, and an ESS. These storage devices systems such as Battery and Flywheel are employed to compensate for the power shortage within the microgrid, principally in the islanded mode when there is an

IJEEI, Vol. 8, No. 1, March 2020: $21-32$ 
unbalance between load power demand generated powers. The parameters of different components of the proposed hybrid system are presented in Table 1. Wind generation and photovoltaic schemes are considered the economic and viable solution for microgrid electrical power generation. In the proposed system the PID controller is implanted for regulated frequency system deviation. The PID controller parameters are determined through an objective function which is resolved using three optimization technique such as GA, $\mathrm{PSO}$, and $\mathrm{KH}$. A brief description of various system components is elaborated below.

Table.1 Parameters of the hybrid energy system

\begin{tabular}{lcc}
\hline Component & Gain $(\mathbf{K})$ & Time constant (T) \\
\hline Wind Turbine Generator & $\mathrm{K}_{\mathrm{WTG}}=1$ & $\mathrm{~T}_{\mathrm{WTG}}=1.5$ \\
Photovoltaic Generator & $\mathrm{K}_{\mathrm{SPV}}=1$ & $\mathrm{~T}_{\mathrm{PV}}=1.8$ \\
Fuel Cell (FC) & $\mathrm{K}_{\mathrm{FC}}=0.01$ & $\mathrm{~T}_{\mathrm{FC}}=4$ \\
Diesel Engine Generator & $\mathrm{K}_{\mathrm{DEG}}=0.003$ & $\mathrm{~T}_{\mathrm{DEG}}=2$ \\
Battery Energy Storage System & $\mathrm{K}_{\mathrm{BESS}}=-0.003$ & $\mathrm{~T}_{\mathrm{BESS}}=0.1$ \\
Flywheel Energy Storage System & $\mathrm{K}_{\mathrm{FESS}}=-0.01$ & $\mathrm{~T}_{\mathrm{FESS}}=0.1$ \\
Aqua Electrolyser (AE) & $\mathrm{K}_{\mathrm{AE}}=0.002$ & $\mathrm{~T}_{\mathrm{AE}}=0.5$ \\
& $\mathrm{~K}_{\mathrm{n}}=0.6$ & \\
\hline
\end{tabular}

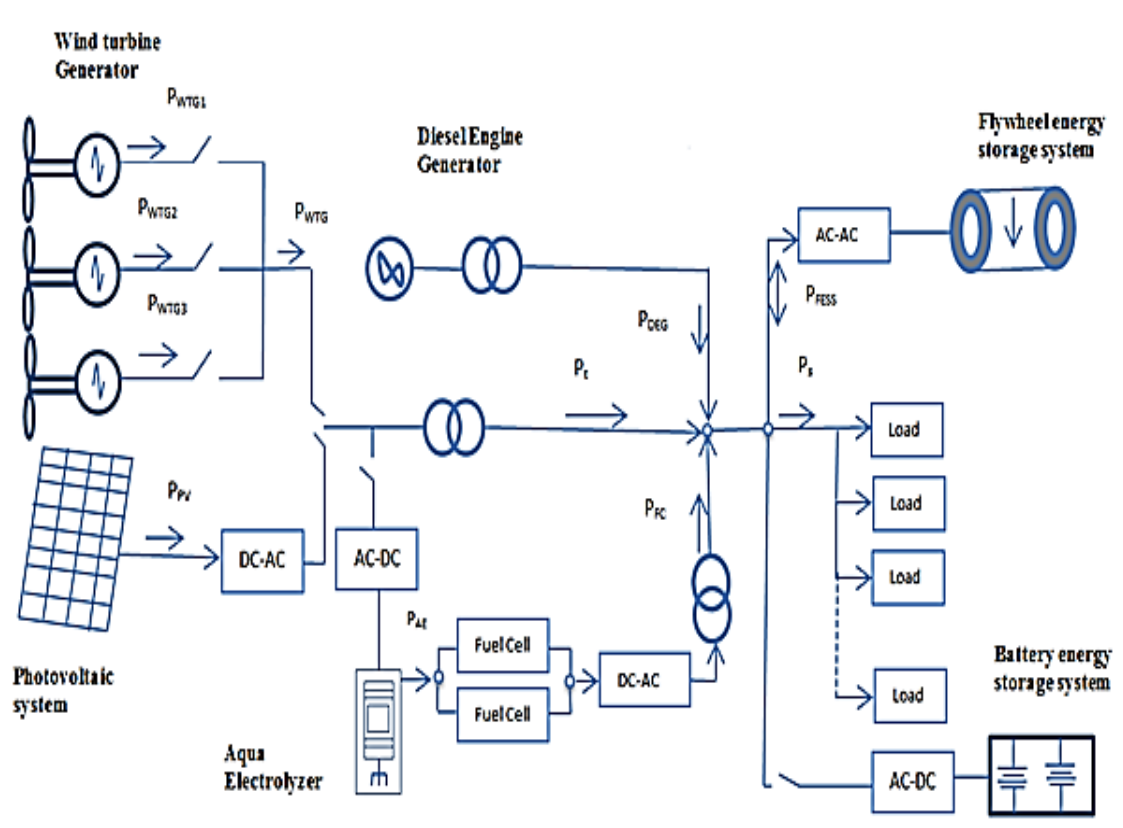

Figure 1. Schematic of hybrid system generation with the storage devices

\subsection{Wind Turbine Generator model}

The Wind Turbine Generator output power changes according to the weather conditions. The transfer function of the WTG is represented in the first-order as given bellow [21-22].

$\mathrm{G}_{\mathrm{WTG}}=\frac{\mathrm{K}_{\mathrm{WTG}}}{1+\mathrm{s} . \mathrm{T}_{\mathrm{WTG}}}=\frac{P_{W T G}}{\Delta P_{W}}$

\subsection{Photovoltaic Generation System}

A Photovoltaic system is composed of number of cells that are connected together in a way to produce direct current and voltage. It is modeled by the first-order transfer function [21-22].

$$
G_{W T G}=\frac{K_{P V}}{1+s . T_{P V}}=\frac{P_{P V}}{\Delta \phi}
$$

\subsection{Fuel Cell power generation model}

The fuel cell system device is considered as an important source of energy whole its principle is to convert the hydrogen into electricity based on chemical reaction. It plays an efficient role in the hybrid 
energy system for its pollution reduction, high performance, and flexible modular structure [5]. The model of the Fuel Cell system is presented by a first-order transfer function as fellow [21-22].

$\mathrm{G}_{\mathrm{FC}}=\frac{\mathrm{K}_{\mathrm{FC}}}{1+\mathrm{s} \cdot \mathrm{T}_{\mathrm{FC}}}$

Where $\mathrm{K}_{\mathrm{FC}}$ and $\mathrm{T}_{\mathrm{FC}}$ present the gain and time constant of the Fuel Cell model.

\subsection{Diesel Engine Generator Model}

DEG is a conventional source of energy widely used to produce electricity as a backup to supply the power deficiency of the hybrid energy system. It works autonomously to supply balance condition between generation power from the wind and solar system and the load demand.

The DEG can be given presented by a simple transfer function order [21-22].

$\mathrm{G}_{\mathrm{DEG}}=\frac{\mathrm{K}_{\mathrm{DEG}}}{1+\mathrm{s} \cdot \mathrm{T}_{\mathrm{DEG}}}=\frac{\Delta \mathrm{P}_{\mathrm{DEG}}}{\Delta \mathrm{f}}$

Where is, $\mathrm{K}_{\mathrm{DEG}}$ the gain constant and $\mathrm{T}_{\mathrm{DEG}}$ is the time constant.

\subsection{Aqua Electrolyser}

An aqua electrolyzer is widely used to produce hydrogen and from the water. It absorbs a part of the power from wind turbine generators and photovoltaic generator to generate hydrogen used by the FC system.It may be modeled using a transfer function in first order [21-22].

$\mathrm{G}_{\mathrm{AE}}=\frac{\mathrm{K}_{\mathrm{AE}}}{1+\mathrm{s} \cdot \mathrm{T}_{\mathrm{AE}}}$

Where $\mathrm{K}_{\mathrm{AE}}$ and $\mathrm{T}_{\mathrm{AE}}$ are gain and time constant of aqua-electrolyzer.

2.6. Power, frequency deviations and control strategy

To maintain the microgrid system stable, the power fluctuation must be controlled. The system frequency varies according to the net power variation. This frequency variation $\Delta \mathrm{f}$ can be determined by (6)[22].

$\mathrm{G}_{\text {Syst }}=\frac{\Delta \mathrm{f}}{\Delta \mathrm{P}_{\mathrm{e}}}=\frac{1}{\mathrm{D}+\mathrm{M} \cdot \mathrm{s}}$

\subsection{Models of Energy Storage Systems}

Energy storage devices play an efficient role in the hybrid energy system in order to absorb the surplus power from renewable energy sources and release to loads if the deficit amount of power. The BESS is slower to charge and discharge; its time constant is limited. On the other hand FESS stores mechanical energy in a rotating flywheel rotor and retrieves it an electrical form. It can supply high power in a short time. The transfer functions of the BESS and FESS can be presented by a first-order transfer function as bellow [21-22].

$\mathrm{G}_{\mathrm{BESS}}=\frac{\mathrm{K}_{\mathrm{BESS}}}{1+\mathrm{s} \cdot \mathrm{T}_{\mathrm{BESS}}}$

$\mathrm{G}_{\mathrm{FESS}}=\frac{\mathrm{K}_{\mathrm{FESS}}}{1+\mathrm{s} . \mathrm{T}_{\mathrm{FESS}}}$

Where $\mathrm{K}_{\mathrm{BESS}}$ and $\mathrm{K}_{\mathrm{FESS}}$ are the gain constants, $\mathrm{T}_{\mathrm{BESS}}$ and $\mathrm{T}_{\mathrm{FESS}}$ are time constants, of BESS and FESS respectively.

\subsection{The stochastic model of the generated power and load}

Small random fluctuations and critical deviation of solar power generation, wind power generation and load demand strength can be expressed as follow (9) [10].

$\mathrm{P}=\left(\frac{\varphi \cdot \eta \cdot \sqrt{\beta} \cdot(1-\mathrm{G}(\mathrm{s}))+\beta}{\beta}\right) \cdot \Gamma=\Gamma \cdot \chi$

Where $\varphi$ is the stochastic component of the power, $P$ represents the wind or solar and load powers, $\beta$ presents the mean value of the power, $\eta$ is a constant normalizes the generated or demand powers $(\chi)$ constant to correspondence per unit (p.u.) level, and $\Gamma$ is time-dependent switching signal with a gain causes sudden fluctuation of the average value for stochastic power [10]. For the wind power generation, the parameters of (9) are:

$\varphi \sim U(-1,1), \eta=0.8, \beta=10, G(s)=\frac{1}{10^{4} . s+1}$

And $\Gamma=0.24 \mathrm{~h}(\mathrm{t})-0.04 \mathrm{~h}(\mathrm{t}-140)$

Where $\mathrm{h}(\mathrm{t})$ is the Heaviside step function. 
For the solar power generation, the parameters of (9) are:

$\varphi \sim U(-1,1), \eta=0.9, \beta=10, G(s)=\frac{1}{10^{4} . s+1}$

And $\Gamma=0.05 \mathrm{~h}(\mathrm{t})+0.02 \mathrm{~h}(\mathrm{t}-180)$

For the demand load, the parameters of (9) are:

$$
\begin{aligned}
& \varphi \sim \mathrm{U}(-1,1), \eta=0.8, \beta=10 \\
& \mathrm{G}(\mathrm{s})=\frac{300}{300 . \mathrm{s}+1}+\frac{1}{1800 . \mathrm{s}+1} \\
& \varphi \sim \mathrm{U}(-1,1), \eta=0.8, \beta=10, \mathrm{G}(\mathrm{s})=\frac{300}{300 . \mathrm{s}+1}+\frac{1}{1800 . \mathrm{s}+1} \\
& \quad \Gamma=\frac{1}{\chi}[0.9 \cdot \mathrm{h}(\mathrm{t})+0.03 \cdot \mathrm{h}(\mathrm{t}-110)+0.03 \cdot \mathrm{h}(\mathrm{t}-130)+ \\
& \quad 0.03 . \mathrm{h}(\mathrm{t}-150)-0.15 \mathrm{~h}(\mathrm{t}-170)+0.1 \cdot \mathrm{h}(\mathrm{t}-190)]+0.02 . \mathrm{h}(\mathrm{t})
\end{aligned}
$$
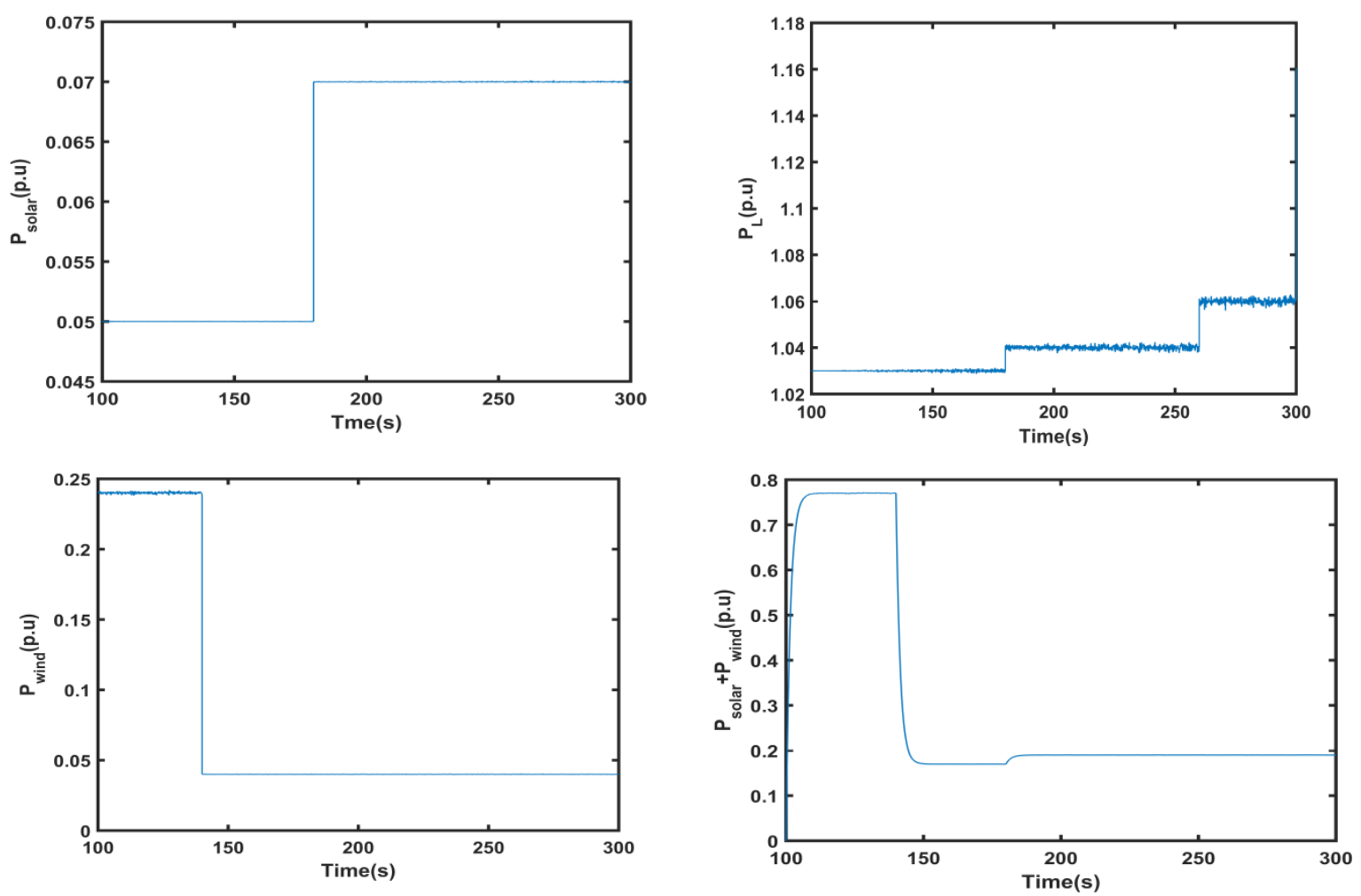

Figure 2. Stochastic generated power from wind speed and solar radiation and load demand

Figure 2 shows the stochastic model of generated power from solar and the wind with the load power which is used in this study. It can be observed that these powers are independent of the controller.

\section{PID CONTROLLER AND OBJECTIVE FUNCTION}

A standard PID control scheme is the most simple often type of control used today in the industry. PID controller is extensively introduced in the industries process due to its simplicity and implementation facility. Many systems use the PID controller to have proved satisfactory. It is widely implemented for many applications in industrial control.

PID controller has been found enough to enhance the stability of the industrial system. Its transfer function is often written in the "parallel form" or in the "ideal form" given by (13) [22].

$G(s)=K_{P}+K_{I} \frac{1}{s}+K_{D} \cdot s$
$G(s)=K_{P}\left(1+\frac{1}{s \cdot T_{I}}+T_{D} \cdot s\right)$ 
Where, $K_{P}, K_{I}$ and $K_{D}$ proportional, integral and derivative gains respectively, $\mathrm{T}_{\mathrm{I}}$ the integral time constant and, $\mathrm{T}_{\mathrm{D}}$ the derivative time constant.

PID control has action control; Proportional, Integral, and Derivative control.

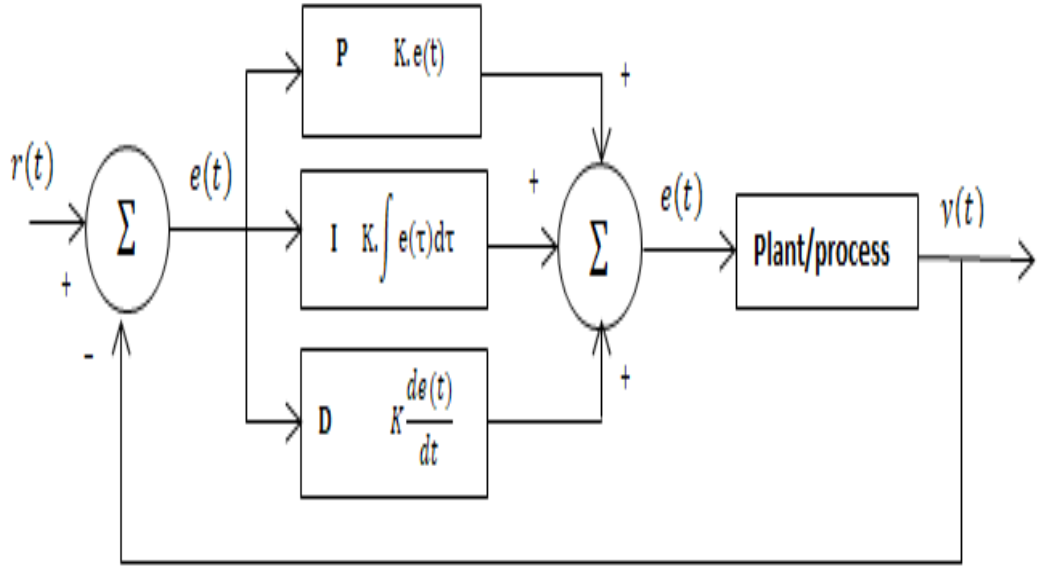

Figure 3. Block of PID controller model

-The proportional action adds an overall control action to the error signal.

-The integral action eliminates the steady-state errors using low-frequency compensation by an integrator.

-The derivative action enhances the transient response by high-frequency compensation of differentiators.

For the effective function of a microgrid, the controller gains need to be optimized. For determining the controller parameters, the objective function in (15) is considered. The integral square of two weighted terms, for minimizing the frequency deviation in the Microgrid system $(\Delta f)$, as well as the incremental control signal $(\Delta u)$ is considered as an objective function in the present study [ 10-16].

$J=\int_{T_{\min }}^{T_{\max }}\left[\mathrm{w}(\Delta \mathrm{f})^{2}+\left(\frac{1-\mathrm{w}}{\mathrm{Kn}}\right)(\Delta \mathrm{u})^{2}\right] \mathrm{dt}$

Where $\mathrm{w}$ represents the importance of Integral square error (ISE) of frequency deviation and the Integral of Squared Deviation of Control Signal, it is taken as0.7. $K n=10^{4}$ is the normalizing constant of the proposed objective function.

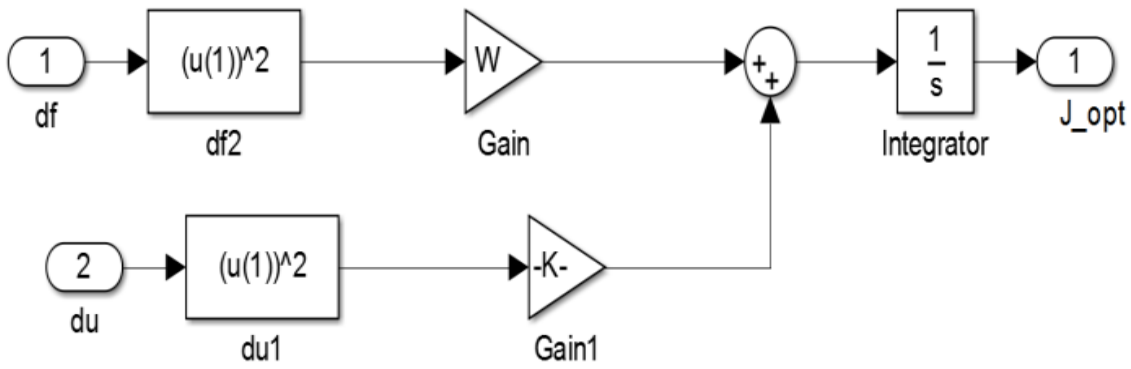

Figure 4. Objective function model in Simulink

This objective function is implemented to calculate the optimal parameters of PID controllers. However, the main objective of the present study is to compare the competence of various optimization techniques in order to find the optimal PID controller parameters which giving the minimum frequency and power deviation.

\section{META-HEURISTIC ALGORITHMS}

Metaheuristics optimization algorithms have been largely used in various areas for solving complexes optimization problems. The main category of metaheuristics algorithm is the bio-inspired. In this section, three different algorithms such as Particle Swarm Optimization, Genetic Algorithm, and Krill Herd are used for PID controller optimization-based frequency and power deviation in hybrid energy systems [23].

IJEEI, Vol. 8, No. 1, March 2020: $21-32$ 


\subsection{Particle Swarm Optimization}

Particle Swarm Optimization is an optimization method that was expended by Eberhart and Kennedy, inspired by fish schooling and the social behavior simulation. PSO has been employed to resolve various optimization problems [24]. This algorithm begins with an initial population (Swarm) of random solution (particles) and a random velocity and random position are initialized [16-19]. Each particle in this population represents set of unknown variables to be determined. The swarm composes of $\mathrm{N}$ particles moving across a D-dimensional search space. The best position of the particles is considered as a possible solution of the considered optimization problem and the velocity of this particle corresponds to the quality or fitness of the associated solution.

The PSO algorithm steps are explained as follows: [24].

1. A random velocity and random position for the population of particle are initialized in D-dimensions search space of the problem.

2. Evaluate the fitness function of each parameter,

3. Compare the present value of fitness function to its best previous value. When the current value is better, then take the best previous position equal to the current position.

4. Identify the particle in the neighbourhood to the best fitness so far, and the current position.

5. Changing the velocity and the position of the particle in accord with the currents velocity and position.

6 . Return to step 2 until a criterion is achieved or end of iterations.

The weighting/inertia factor is added to the velocity equation in order to control the trade-off between the global and local exploration abilities [24]. The standard flowchart of the Particle Swarm Optimization algorithm is displayed in Figure 5 as follows.

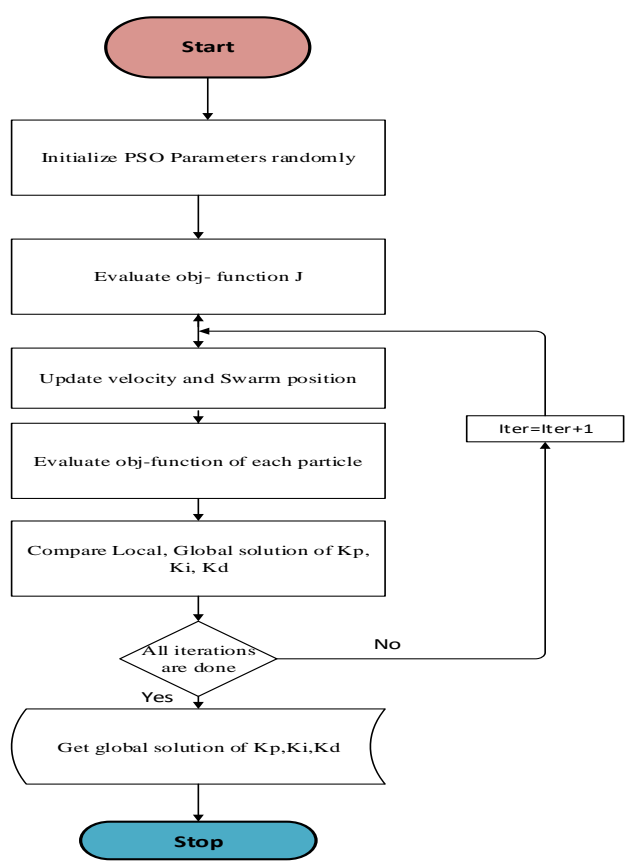

\subsection{Genetic Algorithm}

Figure 5. Standard flowchart of PSO

The GA is an optimization technique based on natural selection and mechanisms of genetic. GA operates with three fundamental operators: reproduction, crossover, and mutation. These operators present the principal part of GA to determine the optimal solution to the optimization problem. For creating a new generation, GA calculates the fitness function of each member of the current population. The parents are selected according to their fitness function. Highly appropriate individuals have a higher probability to be selected for producing the next generation. The new selected individuals are then improved by the application of three basic operators i.e., Selection, Crossover, and Mutation [17, 25-26]. The algorithm is started by creating of a random initial population.

A fitness or objective function is calculated to reflect the goodness of each member of the population [8, $10,15]$. These encoded chromosomes mutate with crossover and a new generation is produced. The chromosome presents a set solution for the objective function.

The fitness function of the new solution is calculated and compared with its previous value. This process repeats for a fixed iteration number. The algorithm is run for many generations and stops when one of the 
stopping criteria is met. The GA is a gradient-free method which has the flexibility to be used for a different kind of optimization issues [27].

\subsection{Krill Herd algorithm}

The new optimization method, so-called krill herd $(\mathrm{KH})$ algorithm according to simulating the Krill individuals herding behaviour in Krill herd using for resolving complicated optimization problems was developed by Gandomi and Alavi (2012) [28-29]. The minimum distance taken by the Krill from its food and the density of here is the objective of the movement. This Algorithm is considered as a metaheuristics optimization technique. The objective function of the krill motion is mostly influenced by the herd density and the distances of each krill individual from food. The time position of a Krill individual is determined according to the movement made by other Krill, the foraging activity and the random diffusion.

These individual krill move toward the best position to the highest density and food. Krill individuals try to maintain high densities and shift toward the best solution. It is recognized that an optimization algorithm should be able to search spaces of arbitrary dimensionality. It can be formulated over time and for Ndimensional space, using the following Lagrangian model [30-31].

$\frac{\mathrm{dX}_{\mathrm{i}}}{\mathrm{dt}}=\mathrm{N}_{\mathrm{i}}+\mathrm{F}_{\mathrm{i}}+\mathrm{D}_{\mathrm{i}}$

Where $\mathrm{N}_{\mathrm{i}}$ is the motion induced by other Krill individuals, $\mathrm{F}_{\mathrm{i}}$ is the foraging motion and $\mathrm{D}_{\mathrm{i}}$ is the physical diffusion of the $\mathrm{i}^{\text {th }}$ Krill individual.

The direction of $\mathrm{Ni}$ which is called ‘ $\mathrm{i}$ is influenced by local density and position of the best krill. Ni is calculated with the following formula:

$\mathrm{N}_{\mathrm{i}}^{\text {new }}=\mathrm{N}^{\text {max }} \alpha_{\mathrm{i}}+\omega_{\mathrm{n}} \mathrm{N}^{\text {old }}$

Where $N^{\max }$ is the maximum induced speed, and $\alpha_{i}$ is defined as:

$\alpha_{\mathrm{i}}=\alpha^{\text {local }}+\alpha^{\text {target }}$

$\omega_{n}$ is the inertia weight of the motion induced in the range $[0,1], N^{\text {old }}$ is the last motion-induced, $\alpha^{\text {local }}$ is the local effect provided by the neighbors and $\alpha^{\text {target }}$ is the target direction effect provided by the best krill individuals.

The Krill Herd Algorithm process can be presented in the flowchart shown in Figure 6 as bellow. Further details about the Krill Herd optimization technique can be found in the literature as in [32]. The Krill Herd algorithm is a bio-inspired and swarm-based algorithm that is able to solve many complex optimization problems and outperform other metaheuristics algorithms [19]. The KH algorithm can closely simulate the krill herding behaviour, and the values of these coefficients were determined using empirical studies in the real-world of krill systems [32].

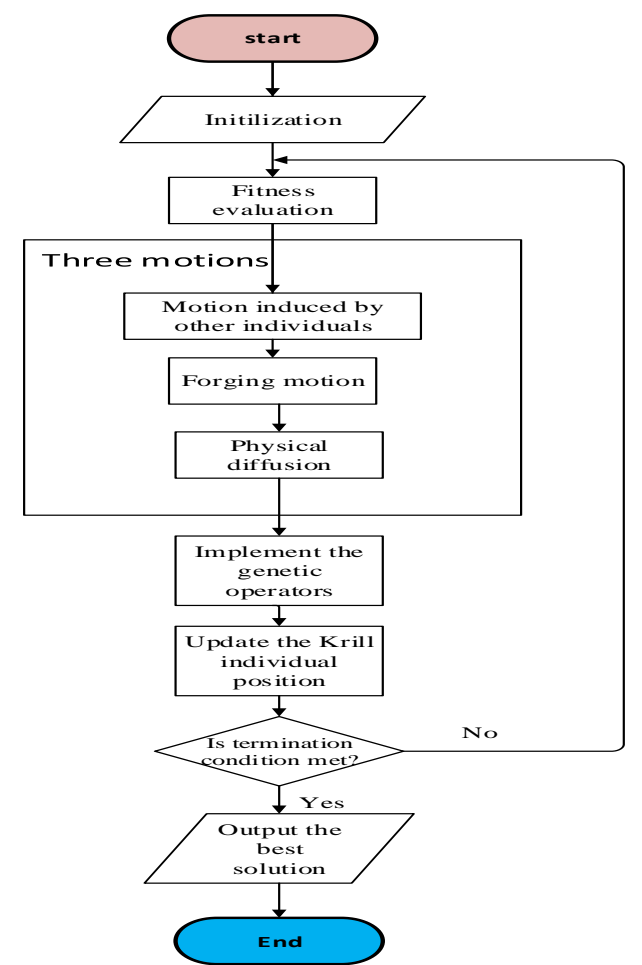

Figure 6. Simplified flowchart of the krill herd algorithm. 


\section{RESULTS AND ANALYSIS}

In this section, the performances of the investigated system are resolved in the time domain analysis. The responses of different compounds of the system are presented with optimum gains PID controller based GA, PSO, and KH. All quantities used in the plots of this section are taken in per unit (p.u.). It presents also the comparison amongst the performances of the controller structure using three optimization methods and their robustness against disconnecting FESS. The objective function is used to adjust all controllers' gains and settings dynamically to minimize the frequency and power deviation.

\subsection{Performance of the proposed system in the nominal condition}

The investigated configuration is run under the normal conditions and the results are shown as in the following figures. The best solutions for objective function obtained by different optimization techniques are reported in Table 2.

\begin{tabular}{cccc}
\begin{tabular}{l} 
Table 2. Best PID controllers using PSO, GA, and KH \\
\hline $\begin{array}{l}\text { Methods/ } \\
\text { controller }\end{array}$
\end{tabular} & $\boldsymbol{K}_{\boldsymbol{P}}$ & $\boldsymbol{K}_{\boldsymbol{I}}$ & $\boldsymbol{K}_{\boldsymbol{D}}$ \\
\hline KH & 6.3937 & 3.7218 & 6.4380 \\
AG & 4.6867 & 4.9998 & 0.4880 \\
PSO & 4.9342 & 2.4297 & 2.5018 \\
\hline
\end{tabular}
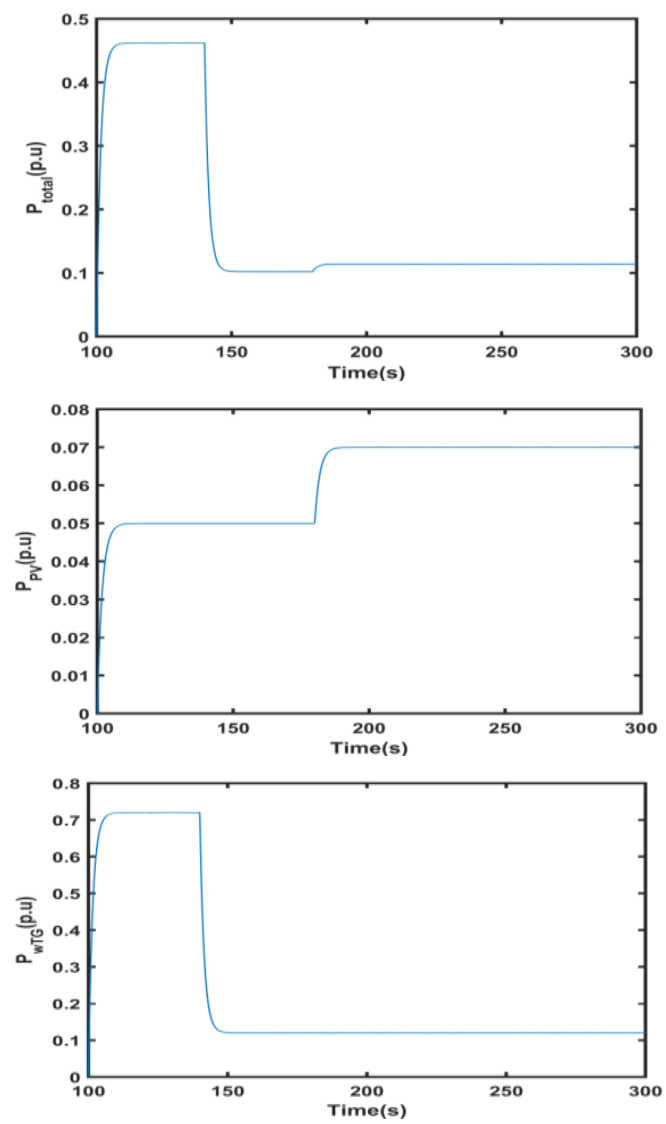

Figure 7. Power generation of the WTGs, PV and total power

The WTGs and PV generators are considered the principal sources to generate power. A part from this power is sent to the AE to generate available hydrogen used as fuel by the FCs system. The system frequency deviation $\Delta f$ is also influenced by the abrupt change in the generated power 

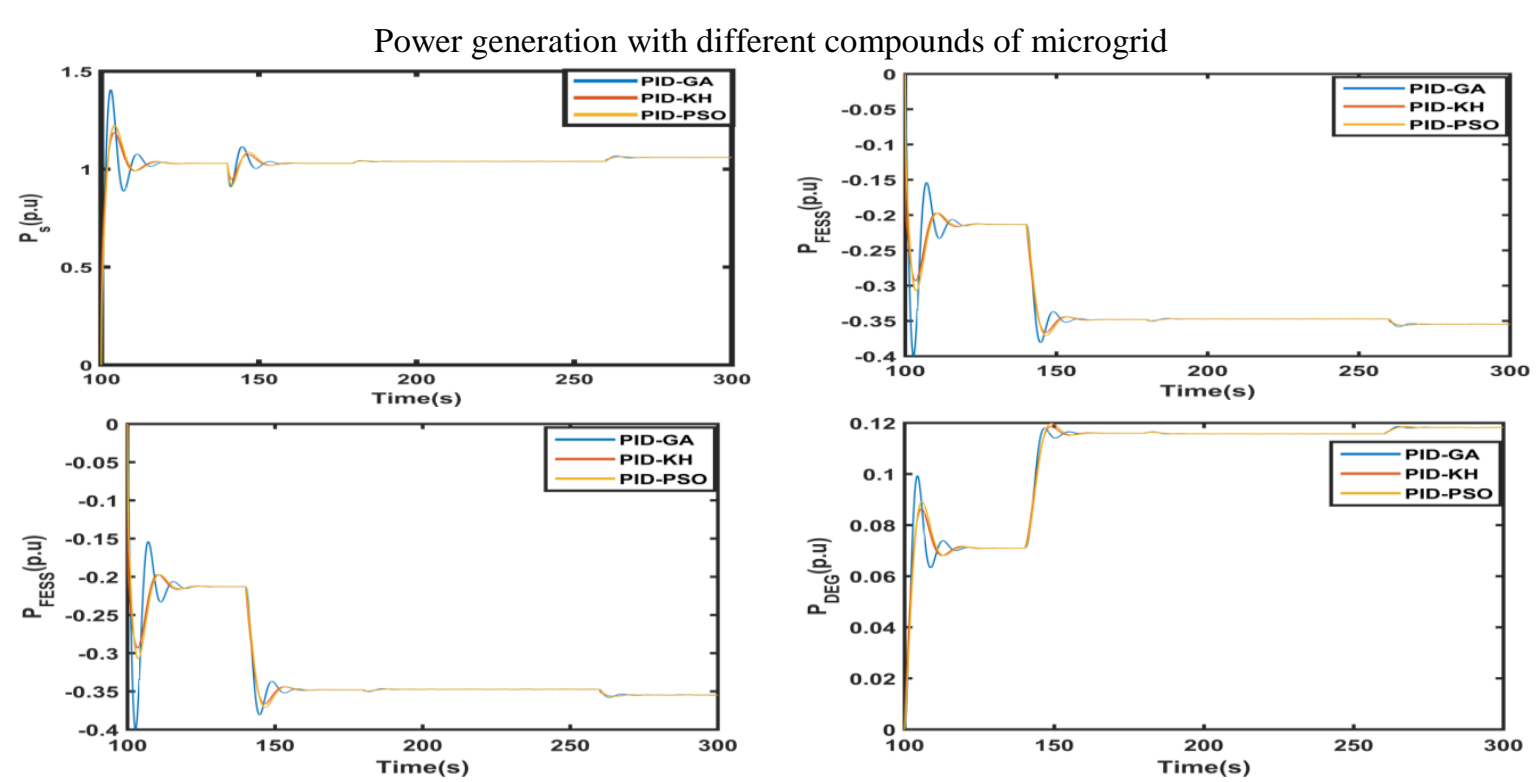

Figure 8. Output powers of the different components of the Microgrid system.

It can be noted that the diesel generator and fuel-cell system used to supply the load power. This shows that the oscillations are greatly reduced using the proposed PID controller based KH algorithm. Then the particle Swarm Optimization technique reduces the fluctuation better in comparison to the Genetic Algorithm. However, it enhances the damping characteristics of the power system and shows best performances of the proposed system.

This bellow figure presents the power and frequency deviation using three optimization techniques like GA, PSO, and KH with the best PID controller parameter.
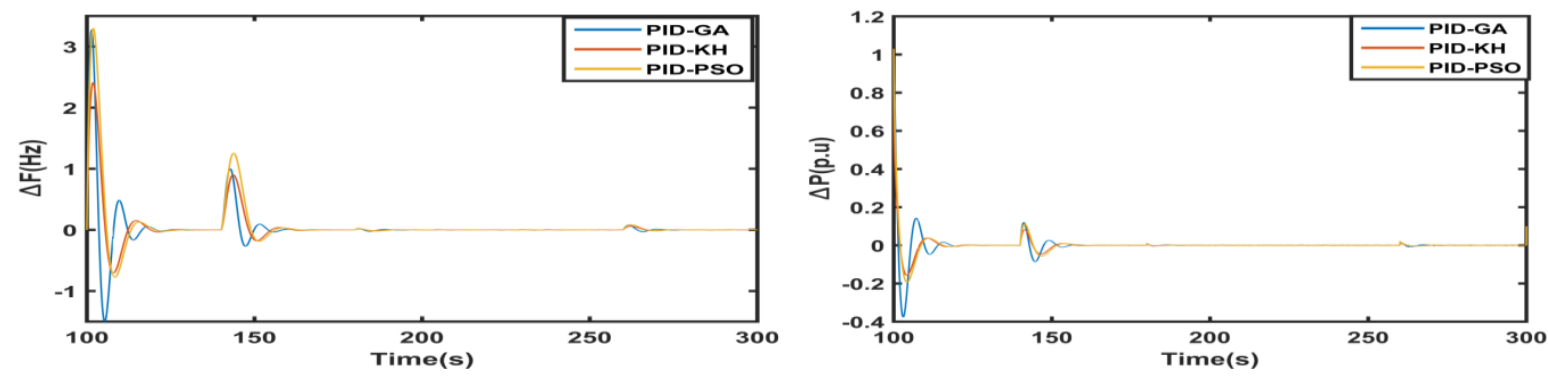

Figure 9. Frequency deviation, and power deviation of the investigated system with best obtained PID controllers

The frequency deviation $(\Delta \mathrm{f})$ and power variation $(\Delta \mathrm{P})$ corresponding to the best-obtained parameters of the proposed controller are displayed in Figure 9. These simulation results show that the frequency and power deviations change according to the sudden change in both generate power and load. It is necessary to note that the controller works to meet the equality between the load and generation with the impact of the weather conditions on the generated power from wind and photovoltaic systems. The fluctuation of frequency and power seriously influences the microgrid stability.

Hence compared to the PID controller optimized using GA, PSO, and $\mathrm{KH}$; it shows that $\mathrm{KH}$ based PID controller greatly enhances the system stability and damping performance for frequency and power deviation compared to GA and PSO tuning PID controller. It is also proved from the shown result that the Particle Swarm Optimization algorithm gives better performances of the system frequency and power control compared to the Genetic Algorithm

\subsection{Robustness Test against Disconnecting Energy Storage System}

For testing the robustness of the proposed PID controller by disconnecting FESS, the system is simulated with and without FESS using PID based KH. This component is considered to have a considerable effect on the proposed system. The performance is better with energy storage devices. Figure 10 and Figure 11 show that the disconnecting energy storage system has a higher impact on system performance. 

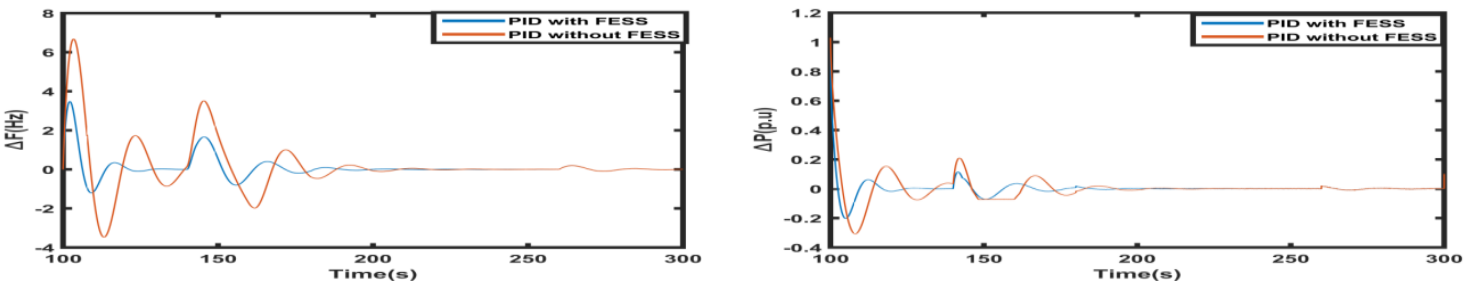

Figure 10. Frequency and Power deviation with disconnecting FESS

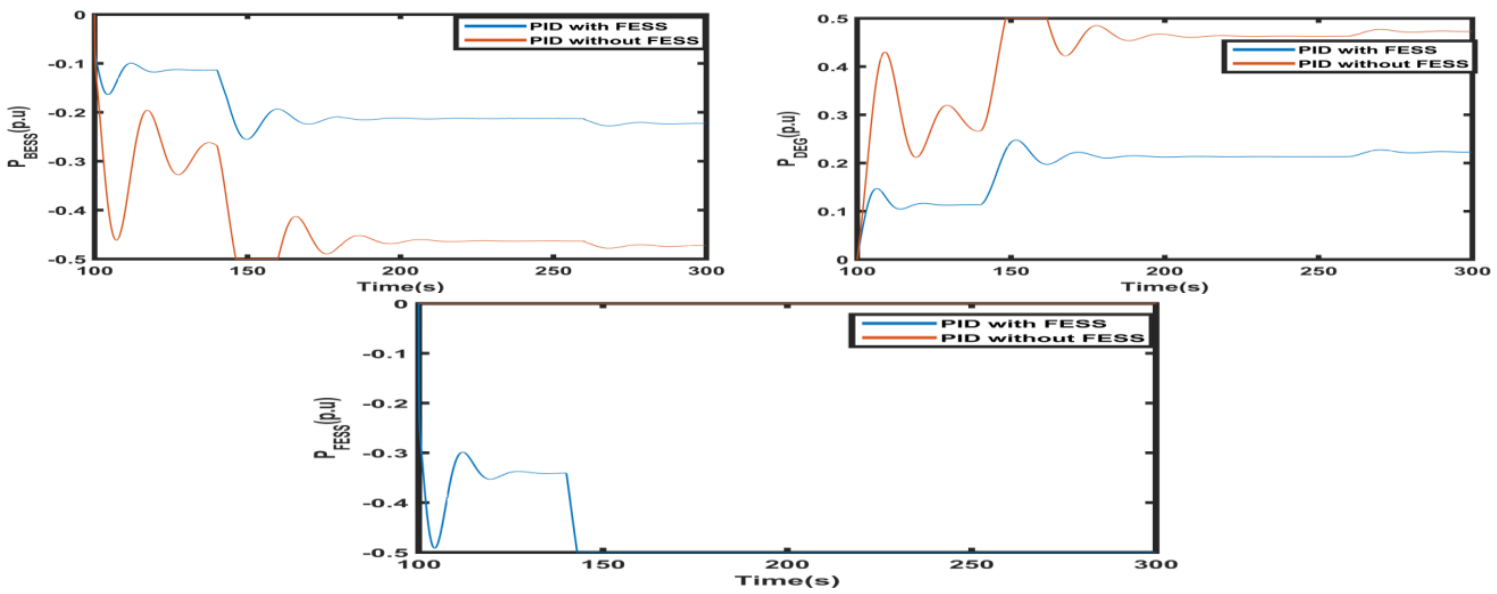

Figure 11. Power generated by different components without FESS

From the above simulation, Figure.10 and Figure 11 show the effect impact of FESS and BESS on frequency and power deviations and the robustness of proposed PID controller based Krill Herd against the changing in loads and generation power.

\section{Conclusion}

This study proposes the frequency control scheme using a PID controller for eliminating the Microgrid frequency fluctuation caused by the disturbances in power generation and load. This proposed controller offers the advantage of reducing the power fluctuation and gives the best performance to the microgrid system. Parameters of the PID controller are tuned using Particle Swarm Optimization, Genetic Algorithm, and Krill Herd algorithms. The Krill Herd technique is better than the PSO and GA in the quality of the solution and giving faster convergence. Simulation results show that the KH algorithm optimizes the PID controller parameters is robust in operation and improves the damping performance of frequency and power deviation system compared to GA and PSO tuning PID controller. Using a PID controller based optimization techniques in the system leads to the enhancement of system stability and robustness as aforementioned in this paper.

\section{REFERENCES}

[1] De Souza Ribeiro, Luiz Antonio, et al. Isolated micro-grids with renewable hybrid generation: The case of Lençóis Island. IEEE Transactions on sustainable energy, vol 2 no.1 pp. 1-11, 2011

[2] N.EL.Y. Kouba and al Automatic Generation Control in interconnected Power System with Integration of wind power Generation using PID Based on Particle Swarm optimization, International Conference on Renewable Energies and Power Quality (ICREPQ'14) Cordoba (Spain), 8th to 10th April 2014

[3] Singh, Vijay P., et al. "Robust H-infinity load frequency control in the hybrid distributed generation system." International journal of electrical power \& energy systems vol 46 pp. 294-305, 2013.

[4] Zhao, C., Xue, D., \& Chen, Y. (2005, July) A fractional order PID tuning algorithm for a class of fractional order plants. In Mechatronics and automation, 2005 IEEE international conference (Vol. 1, pp. 216-221). IEEE.

[5] LEE, Dong-Jing; WANG, Li. Small-signal stability analysis of an autonomous hybrid renewable energy power generation/energy storage system part I: Time-domain simulations. IEEE Transactions on Energy Conversion, vol 23 no.1, pp. 311-320, 2008.

[6] Tomonobu Senjyu, et al A Hybrid Power System Using Alternative Energy Facilities in Isolated Island IEEE TRANSACTIONS ON ENERGY CONVERSION, VOL. 20, NO. 2, JUNE 2005

[7] DAS, DulalCh; ROY, A. K.; SINHA, N. GA based frequency controller for solar thermal-diesel-wind hybrid energy generation/energy storage system. International Journal of Electrical Power \& Energy Systems, vol 43 no.1, pp. 262-279, 2012 
[8] DAS, DulalCh, et al. Genetic algorithm based PI controller for frequency control of an autonomous hybrid generation system. Proc. International Multi conference of engineers and Computer scientists, 2011.

[9] Biswas, Arijit, Swagatam Das, Ajith Abraham, and Sambarta Dasgupta. "Design of fractional-order PI $\lambda \mathrm{D} \mu$ controllers with an improved differential evolution." Engineering Applications of Artificial Intelligence vol 22 no.2 pp. 343-350, 2009

[10] I. Pan and S. Das, "Kriging based surrogate modeling for fractional order control of microgrids," Smart Grid, IEEE Transactions on, vol. 6, no. 1, pp. 36-44, 2015.

[11] Pandey, Shashi Kant, et al. "Frequency regulation in hybrid power systems using particle swarm optimization and linear matrix inequalities based robust controller design." International Journal of Electrical Power \& Energy Systems vol. 63 pp. 887-900, 2014.

[12] Ray, Prakash, Soumya Mohanty, and Nand Kishor. "Small-signal analysis of autonomous hybrid distributed generation systems in presence of ultracapacitor and tie-line operation." Journal of Electrical engineering vol 61 no.4 pp. 205-214. 2010.

[13] Wang, Li, et al. "Analysis of a novel autonomous marine hybrid power generation/energy storage system with a high-voltage direct current link." Journal of Power Sources vol 185 no.2 pp.1284-1292, 2008

[14] TEPLJAKOV, Aleksei. Fractional-order modeling and control of dynamic systems. Springer, 2017.

[15] M. Regad, M. Helaimi, R. Taleb, H. A. Gabbar, and A. M. Othman, "Fractional Order PID Control of Hybrid Power System with Renewable Generation Using Genetic Algorithm," 2019 IEEE 7th International Conference on Smart Energy Grid Engineering (SEGE), Oshawa, ON, Canada, 2019, pp. 139-144

[16] Pan, Indranil, and Saptarshi Das. "Fractional-order fuzzy control of hybrid power system with renewable generation using chaotic PSO." ISA transactions vol. 62 pp. 19-29, 2016

[17] Singh, Jayanti, et al. "Performance Analysis of Fractional Order Fuzzy PID Controller for Hybrid Power System Using WOA." 2018 2nd International Conference on Trends in Electronics and Informatics (ICOEI). IEEE, 2018.

[18] MITCHELL, Melanie. An introduction to genetic algorithms. MIT press, 1998.

[19] Sharaf, Adel M., and A. A. El-Gammal. "A novel efficient PSO-self regulating PID controller for hybrid PV-FCdiesel-battery micro grid scheme for village/resort electricity utilization." 2010 IEEE Electrical Power \& Energy Conference. IEEE, 2010.

[20] Gandomi, Amir Hossein, and Amir Hossein Alavi. "Krill herd: a new bio-inspired optimization algorithm." Communications in Nonlinear Science and Numerical Simulation vol 17 no. 12 p. 4831-4845, 2012

[21] Mohanty, Debidasi, and Sidhartha Panda. "Fractional order based controller for frequency control of hybrid power system." 2019 IEEE International Conference on Sustainable Energy Technologies (ICSET). IEEE.

[22] Ray, Prakash K., Soumya R. Mohanty, and Nand Kishor. "Proportional-integral controller based small-signal analysis of hybrid distributed generation systems." Energy Conversion and Management vol 52 no. 4, p. 19431954. 2011

[23] Gandomi, Amir Hossein, et al. "Metaheuristic algorithms in modeling and optimization." in Metaheuristic applications in structures and infrastructures. Newnes, 2013

[24] Kumari, Naresh, and A. N. Jha. "Frequency Response Enhancement of Hybrid Power System by using PI Controller Tuned with PSO technique." International Journal of Advanced Computer Research 4.1 (2014): 116

[25] C. Houck et al, "A Genetic Algorithm for Function Optimization: A Matlab Implementation", North Carolina State University, 1995.

[26] GUO, Cheng; YANG, Xiaoyong. A programming of genetic algorithm in matlab7. 0. Modern applied science, vol. 5 no. 1 p. 230,2011

[27] Mirzal, Andri, Shinichiro Yoshii, and Masashi Furukawa. "PID parameters optimization by using genetic algorithm." arXiv preprint arXiv:1204.0885, 2012.

[28] Gandomi, Amir Hossein, et al. "Krill herd algorithm for optimum design of truss structures." International Journal of Bio-Inspired Computation vol 5 no. 5, pp 281-288, 2013.

[29] YAGHOOBI, Saber; MOJALLALI, Hamed. Tuning of a PID controller using improved chaotic Krill Herd algorithm. Optik-International Journal for Light and Electron Optics, vol. 127 no. 11 pp. 4803-4807, 2016.

[30] Alikhani, A., Suratgar, A. A., Nouri, K., Nouredanesh, M., \& Salimi, S. (2013, December). Optimal PID tuning based on Krill Herd optimization algorithm. In Control, Instrumentation, and Automation (ICCIA), 2013 3rd International Conference on (pp. 11-15). IEEE.

[31] Asaju La'aro Bolaji, Mohammed Azmi Al-Betar, Mohammed A.Awadallah, Ahamad Tajudin Khader, Laith Mohammad Abualigah,A comprehensive review: krill herd algorithm (KH) and its applications, Applied Soft Computing Journal, vol 49. pp. 437-336, 2016.

[32] Wang, Gai-Ge, et al. "Chaotic krill herd algorithm." Information Sciences vol 274, pp. 17-34, 2014.

IJEEI, Vol. 8, No. 1, March 2020: $21-32$ 